\title{
Upper Gastrointestinal Stent Placement: 8 Years' Experience of a Single Institution
}

\author{
Halit Ziya Dündar' ${ }^{1}$ ๑ Özgen Işık ${ }^{1}, \odot$ Burak Bakar ${ }^{1}, \odot$ Ömer Faruk Özkan² \\ Tuncay Yilmazlar ${ }^{1}$ \\ ${ }^{1}$ Department of Surgery, Uludag University Faculty of Medicine, Bursa, Turkey \\ ${ }^{2}$ Department of Surgery, Canakkale Onsekiz Mart University Faculty of Medicine, Canakkale, Turkey
}

\begin{abstract}
Introduction: Coated and uncoated self-expandable metal stents (SEMS) are increasingly used in the palliation of malignant and benign strictures in the upper gastrointestinal $(\mathrm{Gl})$ tract and in the treatment of postoperative anastomotic leakage and fistulas. The objective of this study was to share the experience of one clinic with upper gastrointestinal tract stent placement. Methods: Patients who underwent upper GI tract SEMS placement between 2009 and 2017 were identified, and patient charts were retrospectively reviewed. The details of patient demographic data, stent type, indication for stent placement, success of stenting, need for stent replacement, morbidity, and mortality were documented.

Results: In total, there were 29 patients with a median age of 57.5 years (min-max: 32-80 years), and 58.62\% were male. There were benign problems in 9 patients. Nine (45\%) of the patients with malignancy had esophageal carcinoma, while the remainder (55\%) had gastric or esophagogastric junction carcinoma. Indications for stent placement were anastomotic leak (41.37\%), esophageal stricture (37.94\%), leak after obesity surgery (10.35\%), esophageal perforation (6.89\%), and tracheoesophageal fistula (3.45\%).

Discussion and Conclusion: SEMS placement is an effective, safe, and minimally invasive method for the palliation of upper Gl tract strictures and the treatment of surgical complications. In this series, the mortality rate in patients who underwent SEMS placement for the treatment of anastomotic leak was high.

Keywords: Self-expandable metal stent; stricture; upper gastrointestinal tract.
\end{abstract}

Coatsen oated and uncoated self-expandable metal stents (SEMS) are increasingly used for the palliation of benign and malignant strictures in the upper gastrointestinal (GI) tract and in the treatment of postoperative anastomotic leaks and fistulas ${ }^{[1]}$.

In the early 1990s, reports of a successful outcome using an uncoated SEMS in a patient with a malignant esophageal stricture led to rapid progression in the use of this method ${ }^{[2,3]}$. As a result of new developments in the manufacturing techniques of covered and uncovered metallic and plastic stents in the last 20 years, stenting is now the treatment of choice in the palliation of malignant esophageal strictures. SEMS is now also used to treat benign strictures and various complications.

The aim of this study was to share the experience of one clinic with SEMS placement in benign and malignant strictures of the upper Gl system.

\section{Materials and Methods}

Patients with different indications who underwent upper Gl tract SEMS placement in the clinic between 2009 and 2017 were identified in the electronic database of the hospital

Correspondence (iletişim): Özgen Işık, M.D. Department of Surgery, Uludag University Faculty of Medicine, Bursa, Turkey Phone (Telefon): +90 5358952305 E-mail (E-posta): ozgen006@yahoo.com 
according to the International Classification of Disease codes for endoscopic procedures. The charts of these patients were reviewed retrospectively. The study was designed and conducted in compliance with the Helsinki Declaration, and patient data were anonymized. Informed consent was obtained from all of the patients concerning medical treatments and interventions. Ethics committee approval was not obtained due to the retrospective design of the study.

The study population consisted of 29 patients aged $>18$ years who had undergone upper Gl (esophagus, stomach, or duodenum) stenting with SEMS. Patients who had undergone SEMS placement at another clinic or medical center were not included in the study. All stents used during the study period were covered SEMS of different brands that were purchased by the hospital. These stents were implanted in the operating room by 2 endoscopists experienced in endoscopy and minimally invasive interventions. Stenting success was evaluated based on the relief of dysphagia secondary to stricture, and clinically bringing perforation or anastomotic leak under control. The details of patient demographic data, type of the stent inserted, indication for stenting, stenting success, need for restenting, and development of procedural complication(s) were evaluated.

Statistical analysis was performed using JMP software, version 12 (SAS Institute Inc., Cary, NC, USA). Categorical variables were expressed as percentages, and continuous variables as mean $\pm \mathrm{SD}$ and medians (minimum-maximum).

\section{Results}

The median age of the 29 patients was 57.5 years (min-max: $32-80$ years). Seventeen $(58.62 \%)$ patients were male. Stents were implanted for benign $(n=9,31.3 \%)$ or malignant $(n=20$, $68.97 \%$ ) lesions. The malignant lesions consisted of primary esophageal cancer ( $n=9,45 \%)$ and gastric and esophagogastric junction cancers $(n=11,55 \%)$. The indications for stenting of all of the patients are provided in Table 1.

In a total of 9 patients, endoscopic reintervention or stent replacement was required. These patients had the following indications: esophageal carcinoma $(n=3)$, gastric carcinoma $(n=1)$, esophagogastric junction carcinoma $(n=1)$, morbid obesity surgery $(n=1)$, esophageal perforation $(n=1)$, peptic ulcer perforation $(n=1)$, and short esophagus $(n=1)$. Restenting was required due to persistence of anastomotic leak or perforation in 7 patients, the presence of a tracheoesophageal fistula in 1 patient, and the persistence of malignant stenosis in 1 patient.

The average stenting success rate was 79.3\%. Major morbidity did not develop during the early postoperative period re-
Table 1. Indications for stenting

\begin{tabular}{|c|c|c|}
\hline Diagnosis & n (\%) & $\begin{array}{l}\text { Indication for SEMS } \\
\text { placement }\end{array}$ \\
\hline \multirow[t]{3}{*}{ Esophageal carcinoma } & $9(31.1)$ & Anastomotic leak $(n=1)$ \\
\hline & & $\operatorname{TEF}(n=1)$ \\
\hline & & Stricture $(n=7)$ \\
\hline \multirow[t]{2}{*}{ Gastric carcinoma } & $6(20.7)$ & Anastomotic leak $(n=5)$ \\
\hline & & Stricture $(n=1)$ \\
\hline \multirow{2}{*}{$\begin{array}{l}\text { Esophagogastric } \\
\text { junction carcinoma }\end{array}$} & $5(17.2)$ & Anastomotic leak $(n=3)$ \\
\hline & & Stricture $(n=2)$ \\
\hline \multirow[t]{2}{*}{ Morbid obesity } & $3(10.3)$ & Sleeve gastrectomy leak $(n=2)$ \\
\hline & & Gastric bypass leak $(n=1)$ \\
\hline Achalasia & $1(3.45)$ & Esophageal perforation \\
\hline Peptic ulcer perforation & $1(3.45)$ & Anastomotic leak \\
\hline Short esophagus & $1(3.45)$ & Anastomotic leak \\
\hline Polyposis syndrome & $1(3.45)$ & Anastomotic leak \\
\hline Crohn's disease & $1(3.45)$ & Esophageal stricture \\
\hline Boerhaave syndrome & $1(3.45)$ & Esophageal perforation \\
\hline
\end{tabular}

TEF: Tracheoesophageal fistula.

lated to application of SEMS. The most frequently observed minor morbidity was retrosternal pain $(n=27,93.1 \%)$. The mortality rate was $20.68 \%(n=6)$. Five patients died as a result of septic complications secondary to anastomotic leak, and 1 was lost following pneumosepsis that developed related to a tracheoesophageal fistula.

\section{Discussion}

As has been reported in many literature studies, stents have an important role in the palliation of malignant and benign strictures of the upper Gl tract, and in the treatment of postoperative anastomotic leaks and fistulas ${ }^{[1]}$. In our series, we also attained results that support SEMS as a safe and successful method for palliation of malignant and benign strictures and control of leaks developing following bariatric surgery. However, a higher mortality rate was detected among patients in whom stenting was applied in the management of an anastomotic leak, which is an important surgical complication.

Stents have been used for many years for Gl system diseases. In a study conducted by Domschke et al. ${ }^{[2]}$, the authors reported successful results using a metallic stent in a patient with a malignant esophageal stricture, and subsequently, there has been rapid progression in its application. In recent years, in addition to malignant esophageal strictures, stent placement has increasingly been used in the treatment of many complications, including benign strictures and anastomotic leaks [2, 3]. In our study, SEMS was found to be effective in the palliation of strictures; however, 
the higher mortality rate observed after stent treatment of anastomotic leaks was noteworthy. We suspect that delay in SEMS placement may have been a possible cause. In the event of a suspected anastomotic leak, we believe that a careful endoscopic evaluation and early application of SEMS will help to reduce the rate of mortality.

Currently, various types of stents are used. Stents are classified as coated or uncoated. Coated stents have been reported to be more useful ${ }^{[4-6]}$. A coated SEMS serves as a mechanical barrier in the management of fistulas and leaks. This feature led to the use of a coated SEMS in the treatment of tracheoesophageal fistula ${ }^{[7]}$. Several studies have examined the effect of SEMS implantation on survival. Following stent placement in the management of a malignant disease, an average survival time of 318 days was reported in patients who received concomitant radiotherapy and chemotherapy, and 68 to 77 days in patients who did not ${ }^{[8,9]}$.

The major complications of SEMS placement consist of bleeding, aspiration pneumonia, tracheal compression, perforation, and tracheoesophageal fistula, while reported minor complications include gastroesophageal reflux, feeling the presence of a foreign body, inadequate expansion of the stent, stent migration, formation of granulation tissue, food impaction, hiccups, failed stent placement, and luminal occlusion due to tumor ingrowth or overgrowth ${ }^{[10,}$ 11]. In our study, no major complication was experienced. Retrosternal pain was observed in $93.1 \%$ of our cases. Similarly, Sapmaz et al. ${ }^{[11]}$ reported retrosternal pain in most of their patients. There was no instance of stent migration in our cases. The most important reason is that we used internally coated stents with a metal external surface. This metal exterior enables the stent to settle firmly on the mucosa, and displacement is avoided ${ }^{[12]}$.

The most important limitation of our study is its retrospective design. The limited number of cases is another disadvantage; however, the consistency of successful outcomes of SEMS placement for various indications obtained by experienced endoscopists at a tertiary health center is a clinically strong point.

In conclusion, the use of SEMS is a safe, effective, and minimally invasive method used in the palliation of upper $\mathrm{Gl}$ tract strictures and their surgical complications. We think that in the management of a suspected anastomotic leak, early endoscopic evaluation and implantation of SEMS will increase the treatment success rate for this complication and decrease the mortality rate.

Peer-review: Externally peer-reviewed.
Authorship Contributions: Concept: O.I., T.Y.; Design: Ö.F.Ö., H.Z.D., O.I., T.Y.; Data Collection or Processing: B.B., O.I., H.Z.D., E.Ö.; Analysis or Interpretation: O.I., B.B., E.O.; Literature Search: T.Y., E.O., H.Z.D., Ö.F.Ö., O.I.; Writing: O.I., B.B., H.Z.D.

Conflict of Interest: None declared.

Financial Disclosure: The authors declared that this study received no financial support.

\section{References}

1. Sharma P, Kozarek R; Practice Parameters Committee of American College of Gastroenterology. Role of esophageal stents in benign and malignant diseases. Am J Gastroenterol 2010;105:258-73. [CrossRef]

2. Domschke W, Foerster EC, Matek W, Rödl W. Self-expanding mesh stent for esophageal cancer stenosis. Endoscopy 1990;22:134-6. [CrossRef]

3. Eroglu A, Turkyilmaz A, Subasi M, Karaoglanoglu N. The use of self-expandable metallic stents for palliative treatment of inoperable esophageal cancer. Dis Esophagus 2010;23:64-70.

4. Saranovic Dj, Djuric-Stefanovic A, Ivanovic A, Masulovic D, Pesko P. Fluoroscopically guided insertion of self-expandable metal esophageal stents for palliative treatment of patients with malignant stenosis of esophagus and cardia: comparison of uncovered and covered stent types. Dis Esophagus 2005;18:230-8. [CrossRef]

5. Vakil N, Morris Al, Marcon N, Segalin A, Peracchia A, Bethge $\mathrm{N}$, et al. A prospective, randomized, controlled trial of covered expandable metal stents in the palliation of malignant esophageal obstruction at the gastroesophageal junction. Am J Gastroenterol 2001;96:1791-6. [CrossRef]

6. SabharwalT, Hamady MS, Chui S, Atkinson S, Mason R, Adam A. A randomised prospective comparison of the Flamingo Wallstent and Ultraflex stent for palliation of dysphagia associated with lower third oesophageal carcinoma. Gut 2003;52:922-6.

7. Bethge N, Sommer A, Vakil N. A prospective trial of self-expanding metal stents in the palliation of malignant esophageal strictures near the upper esophageal sphincter. Gastrointest Endosc 1997;45:300-3. [CrossRef]

8. Wen L, Quan H, Li L, Huang C, Chen X, Yang Y, et al. The clinical research of the endoscopic sequential treatment for patients with intermediate-advanced esophageal cancer: a randomized clinical trial. Med Oncol 2014;31:284. [CrossRef]

9. Mariette C, Gronnier C, Duhamel A, Mabrut JY, Bail JP, et al; FREGAT Working Group-FRENCH-AFC; FREGAT Working Group-FRENCH-AFC. Self-expanding covered metallic stent as a bridge to surgery in esophageal cancer: impact on oncologic outcomes. J Am Coll Surg 2015;220:287-96. [CrossRef]

10. Talreja JP, Eloubeidi MA, Sauer BG, Al-Awabdy BS, Lopes T, Kahaleh $M$, et al. Fully covered removable nitinol self-expandable metal stents (SEMS) in malignant strictures of the esophagus: a multicenter analysis. Surg Endosc 2012;26:1664-9.

11. Sapmaz F, Basyigit S, Uzman M, Nazlıgul Y. Evaluation of efficacy and safety of our experiences with internally covered self-expandable metal stent in cases with malignant esophageal dysphagia. Akademik Gastroenteroloji Dergisi 2015;14:95-100.

12. Yu Q, Mulmi S, Liu Y. The Placement of Esophageal Stents in Different Esophageal Disease Related Conditions-A Review. Open Journal of Gastroenterology 2016;6:117-26. [CrossRef] 